\title{
MED ANTROPOGEOGRAFIJO IN SOCIALNO GEOGRAFIJO NA LJUBLJANSKI UNIVERZI
}

\author{
Vladimir Klemencic*
}

IZVLEČEK

UDK 911.3(497.12)

Članek obravnava razvoj geografske misli in proučevanja na podroxju antropogeografije oziroma socialne gcografije $\mathrm{v}$ Sloveniji. Našteva temeljna dela in osebe, ki so k preobrazbi prispevali.

\section{ABSTRACT}

UDC 911.3(497.12)

FROM ANTHROPOGEOGRAPHY TOWARDS SOCIAL-GEOGRAPHY AT THE UNIVERSITY OF LJUBLJANA

The article discusses the development of geographycal thoughts and studies within antropogeography and social-geography. Names and projects are mentioned in conjunction with changes towards modern geographycal thinking and handling.

Ko poskušamo osvetliti razvojno pot slovenske geografije, predvsem antropogeografije in socialne geografijc, v zadnjih sedemdesetih letih, od ustanovitve Gcografskega instituta na slovenski univerzi dalje, lahko z zadovoljstvom ugotovimo, da danes na tem podroxju prevladujejo pozitivne tendence. Tako imenovani družbenogeografski clement, katerih rezultat je s človekovim delom v kulturno pokrajino preoblikovana prirodna pokrajina, skoraj nikoli v slovenski geografiji niso bili obravnavani izolirano zunaj prostora; skoraj v vseh znanstvenih delih lahko sledimo, ceprav ne vselej uspesnemu, iskanju zvez med družbenogeografskimi in fizißnogeografskimi elementi. Kot vidimo, družbena geografija ni imela svojega mesta le v družbenogeografskih Studijah, temveč tudi $\mathrm{v}$ takih, ki so nosile fizix̌nogeografski ali regionalnogeografski naslov. Če pregledamo raziskovalna dela, objavljena v revijah ali v posameznih knjigah tako doma kot tudi po svetu, lahko že $z$ majhnim naporom izlušcimo razvoj kulturne pokrajine kot uxinek clovekovega bivanja in dela, in sicer od tipa pokrajine klasiene statistične agrarne družbe, ki je bila jasno izražena §e do prvih treh desetletij XX. stoletja, pa do tipa pokrajine moderne, fleksibilne, industrijske družbe, ki pa z nekaterimi inovacijami visoke tehnologije, sicer omejene v SR Sloveniji, na majhen prostor metropolitanskega tipa, že prehaja v moderno informacijsko družbo.

* Dr., univ.prof., Oddelek za geografijo, Filozofska fakultcta, 61000 Ljubljana, Aškeræeva 12 , YU. 
Geografija se tako na ljubljanski univerzi kot tudi drugod v Evropi in po svetu ni mogla izogniti polemikam o nalogah in definicijah oziroma o predmetu geografske znanosti; pri tem je bilo $n$ ajvec diskusije prav o razumevanju tistih podrocij geografije, ki ne sodijo v regionalno ali fizið̌no. Ko obravnavamo razprave o vprasanju antropogeografije oziroma socialne geografije, lahko njun razvoj razdelimo v tri razdobja. Prvo razdobje, ki sodi v prva tri desetletja od ustanovitve Geografskega instituta na ljubljanski univerzi pa do petdesetih let, je pravzaprav potekalo brez pravih diskusij in razprav, saj je prof. Melik v svoji osebnosti povezoval vse tri vidike; regionalnega, fizičnogeografskega, antropo- in socialnogeografskega. Za to tako imenovano Melikovo obdobje geografije je znaxilno opisovanje slovenske pokrajine $\mathrm{z}$ razlago fizičnogeografskih procesov in posameznih elementov slovenske pokrajine (reliefa, klime, vodovja, manj pa že vegetacije). Ob obravnavi rezultatov človekovega dela pri oblikovanju kulturne pokrajine se je tako imenovana Melikova sola lotevala vsega, kar je bilo na slovenski narod nacionalno pomembno. $\mathrm{V}$ to obdobje sega tudi gcografska obravnava manjšinskih problemov v okviru celotnega slovenskega etni¿nega prostora ali s Slovenci poseljene pokrajine, ne glede na to, kateri državi so pripadali posamezni deli slovenskega etnixnega ozemlja. Pri tem moram poudariti zaslugo prof. Melika, da mu je že tedaj uspelo prikazati Slovence kot integralni in aktivni del kulturne pokrajine $\mathrm{z}$ vscmi problemi zgodovinskega razvoja in tedanjimi družbeno-ekonomskimi ter političnimi procesi. Meliku gre pravzaprav zasluga, da se danes lahko seznanjamo s tedanjimi problemi kulturne pokrajine, kjer je prevladovalo alpsko pastirstvo na nižji agrarno-gospodarski in tehnološki ravni. Njegova zasluga je tudi, da je predstavil enega od zelo pomembnih pokrajinskih elementov na Slovenskem, kazalec ki je danes simbol slovenske pokrajine. V Melikovo obdobje med prvo in drugo svetovno vojno sodi ravno tako tudi pobuda za osvetlitev spicmemb na socialnem in ekonomskem pođroxju in v zvezi s tem prve inovacije neagrarne družbe $v$ prostorskih strukturah slovenskega podeželja. Med tedaj zelo pomembna dela, v katerih je prof. Mfelik ob pomoxi prof. IlesiŁa predstavil probleme podeželja, sodijo tudi Studije o strukturi prebivalstva, v katerih je prikazal tedaj previadujox pojav na slovenskem podežclju, agrarno prenaseljenost. $V$ to razdobje sodijo tudi prizadevanja na podrocju proučevanja agrarnih naselij, mest in sistemov poljske razdelitve.

Prav pri tem proučevanju socialno-ekonomskih struktur in agrarne prenaseljenosti se $\mathrm{v}$ slovenski geografiji kažejo prvi znaki uveljavljanja sociainogeografskega aspekta. Ravno s temi deli prehajamo od opisovanja $k$ poskusom vzročno-posledičnega načina obravnave dolocenega pojava v prostoru. To je doba, ko smo v slovenski geografiji zaznali, da je razvoj kulturne pokrajine ozko povezan s spreminjanjem socialnih skupin agrarne družbe v socialne skupine neagrarne družbe in z uveljavljanjem novih skupin prebivalstva. Razlið̌ne obravnave priðenjajo te skupine spreminjati vse do najnovejß̌ga razdobja; te skupine pa so prispevale $\mathrm{k}$ vse večjemu uveljavljanju prostorskih struktur urbane družbe. Med vodilne nosilce preobrazbe, ki so se dane 
predmet raziskav, sodijo socialne skupine dnevnih migrantov, polkmetov, delavcev na zacasnem delu $v$ tujini ter lastnikov poxitniłkih bivališc, ki so nosilci transformacije kulturne pokrajine $\mathrm{v}$ procesu industrializacije, modernizacije kmetijske proizvodnje, razvoja turizma in v najnovejక̌em Casu tudi razlixnih oblik malega gospodarstva, od najosnovnejsih oblik pa do takih z visoko moderno tchnologijo. Pri tej usmeritvi je antropo-socialno geografijo prav gotovo pospesilo delo prof. Ileš‘ desctih letih $\mathrm{z}$ ux́nimi pripomočki vnesel $\mathrm{v}$ uxno-vzgojni proces informacije o teoretsko-metodoloski zasnovanosti antropo-socialne geografije, geografije naselij, geografije prebivalstva in gospodarske gcografije. Morda je razdobje utrjevanja na geografske vede razdeljene geografije trajalo predolgo. Prav pomanjkanje poskusov sinteti¿ne obravnave geografskih struktur in geografskih procesov ter s tem povezane preobrazbe kulturne pokrajine je edprlo ob poskusih uveljavljanja moderne socialne geografije diskusijo o definiciji in tcoretsko-metodoloski opredeljenosti gcografije, iz katerc se postopoma $v$ antropo-socialni geografiji uveljavlja moderna socialna geografija. Ta je zasnovana na prouxevanju učinkovanja socialnih skupin prek človekovih dejavnosti (dela, bivanja, cskrbe, izkorišanja prostega Casa, izobraževanja, skupnega delovanja $\mathrm{v}$ prometu) na proces preobrazbe pokrajine; to je tisti koncept, ki z vzroxno-posiedienim pristopom opredeljuje menjave funkcij in procesov $v$ razvoju preobrazbe prostora. To je koncept, s katerim so se srednjeevropski geografi z rezultati svojih prouðevanj uspešno vkljuxili v prostorsko planiranje na raziixnih podioxjih ekologije, varovanja okolja in planiranja razvoja mestne ter podežeiske pokrajine, bodisi kot celovitih kompleksov ali kot posameznih elementov. $\mathrm{V}$ tem socialno-geografskem konceptu so naravno-geografske danosti materiaina osnova za clovekovo živijerije. Ker geografom, ne le pri nas, temvex tudi po svetu, ni uspelo izoblikovati metodologije za vrednotenje naravnih virov, smo tudi sorazmerno pozno vkljucili v koncept in vsebino svojih raziskav tiste probleme geografske narave, ki si jih je clovek nakopai v vexini industrializiranih in urbaniziranih dežel s svojim nesmoternim ravnanjem $z$ naravo.

Vzrok za to pa lahko išcemo tudi v podcenjevanju nalog geografa pri njegovem raziskovalnem delu, povezanim s terenskim opazovanjem dogajanj v mestni in podeželski pokrajini. Jugoslovanski geografi smo posvetili vse premalo pozornosti kopiženju neagrarnih dejavnosti in prebivalstva po mestih ter praznjenju obSirnih, za kmetijstvo in druge dejavnosti primernih podroxij. Tako je ponekod $v$ Jugoslaviji podvržena praznjenju in razkroju kulturne pokrajine skoraj polovica poseljenega prostora, ki ga tako prepuscamo eroziji in ogozdovanju ter s tem odtegujemo kmetijskemu gospodarstvu. Če bi vse te pojave vzroæno-posledično proucevali in jih spremljali glede na reagiranje cloveka v prostoru, bi s svojimi opozorili lahko marsikaj dosegli za izboljŁanje socialnega položaja prebivalstva. S pomoxjo oblikovanja raziskovainih metod, ki bi imele vecji poudarek na terenskem prouðevanju, to je na takem konceptu raziskav, ki se priXenjajo z opazovanjem na terenu in se prek zapletenih kvantitativnih 
ter kvalitativnih analiz statistiðnega gradiva vraðajo do ponovnega iskanja potrditve svojih raziskav $v$ konkretni pokrajini, in ob konfrontaciji s konkretnimi socialnimi skupinami, ki so nosilec zaželenih in nezaželenih posledic v prostoru, pa si geografija ne bi pridobila zaupanja samo med prizadetim prebivalstvom, ampak bi lahko ponovno utrdila svoje mesto $v$ izobraževanju vseh stopen $j$ in $s$ tem tudi $v$ kulturni vzgoji cloveka.

Socialnogeografski pristop v geografiji sega pravzaprav že v XIX. stoletja, vendar se v svoji kompleksni obliki z oblikovanimi teoretskimi in metodoloskimi izhodiši pojavlja §ele tedaj, ko so $\mathrm{v}$ prostoru zacele delovati zakonitosti skupine neagrarnega prebivalstva predvsem ob hitrem nazadovanju deleža agrarnega prebivalstva. V sedemdesetletnem razdobju razvoja geografije na ljubljanski univerzi so se, podobno kot drugod po svetu, poleg antropogeografije in socialne geografije pojavljale se oznake kot kulturna geografija ali ekonomska geografija. Pogosto se je pod razlicnim imenom skrivala podobna vsebina, pa tudi podobni koncepti. Prav gotovo je temeljna prelomnica $v$ razvoju tako imenovane antropo-socialne geografije prehod od bolj umirjenega, na agrarni družbi slonecega razvoja kulturne pokrajine k prevladi fleksibilne, neagrarne družbe $\mathrm{z}$ moxno diferencirano delitvijo dela in oblikovanjem vse vexjega števila socialnih skupin. Tako se nam včasih še na neznane načine, zaradi slabega poznavanja vzrokov in posledic njihovega delovanja $v$ prostoru, hitro odpirajo novi prostorski problemi. V ZDA se je $\mathrm{v}$ teh hitrih procesih prestrukturiranja družbe iz agrarne $v$ urbano uveljavila tako imenovana socialna ekologija, ki je že dala slutiti, da ravnanja dolocenih socialnih skupin odpirajo v naravi nove probleme in tudi ekološko ogrožajo pokrajino (Park, Burger, McKanzic). Srednjo Evropo je tak proces zajel §ele v povojnem razdobju, §e zlasti v §estdesetih letih. Ker so želcli tedaj vodilni geografi prodreti $v$ bistvo problemov novih, dinamixnih, socialnih in prostorskih procesov, se je zacela razvijati tako na Švedskem kot na Nizozemskem, z!asti pa $\checkmark$ ZR Nemčiji in Avstriji posebna socialno-geografska §ola, katere rezultat je knjiga "Socialna geografija", delo skupine avtorjev Ruperta, Schăfferja, Maierja in Pesserja, ki je temeljila na njihovih lastnih empirixnih raziskavah in zlasti na spoznanjih Hartkeja in Bobeka.

V Sloveniji se je po mojem mnenju socialnogeografski aspekt $v$ geografiji uveljavil, ob upostevanju specifienih pogojev oblikovanja urbane, industrijske ali informacijske družbe, podobno kot npr. v ZDA, na Nizozemskem, v ZRN, Avstriji in Švici, vendar $v$ specifični obliki, in sicer zaradi potrebe po razlaganju zelo zapletenih in znaxilnih procesov preobrazbe kulturne pokrajine, ki se danes potekajo na zelo razlixne nacine v zelo razlixnih geografskih okoljih alpskega, panonskega, dinarsko-kraškega in severnojadranskega submediteranskega prostora. Slovenska pokrajina je zdiferencirana znotraj teh geografskih okolij Łe na obmoxja, kjer so se $\mathrm{z}$ razlixno dinamiko in $\mathrm{v}$ razlienih casovnih intervalih uveljavljale zakonitosti neagrarne družbe, to pa ne le 
zaradi prirodnih pogojev in zgodovinskega razvoja, ampak tudi zaradi različnega usmer janja gospodarskega razvoja po gospodarskih panogah. V SR Sloveniji pa je కe

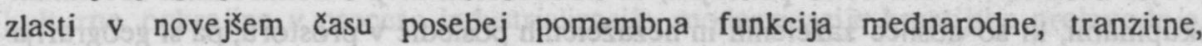
prometno- prostorske lege. Zaradi tega je SR Slovenija za Jugoslavijo pomembna tudi kot obmejna regija na prehodu med manj in bolj razvito Evropo. V kratkih dvajsetih letih se je uveljavil koncept policentriðnega razvoja, ki celotnemu slovenskemu prostoru zagotavlja, ce že ne enak razvoj, pa vsaj povsod bolj ali manj hitro dinamiko uveljavljanja uxinkov urbane družbe samega prostora SR Slovenije kot tudi vse mođ̌neǰ̌ega prekomejnega vpliva zaradi bolj ali manj načrtnega gospodarskega, kulturnega in politiðnega prekomejnega sodelovanja v okviru skupnosti Alpe - Jadran in tudi že tendenc evropske integracije narodov in regij. $\mathrm{V}$ takih razmerah slovenskega prostora smo morali, ce hocemo opredeliti novo nastale procese in znotraj teh tudi prostorske strukture, ki so izraz razlicnih faz in intenzivnosti ter smeri uveljavljanja neagrarnega prebivaistva $\mathrm{v}$ procesu prestrukturiranja družbe iz agrarne $\mathrm{v}$ industrijsko in terciarno, opustiti opisovanje ali pa proucevanje posameznih pojavov, izoliranih zunaj kompleksa družbeno-ekonomskih procesov in spreminjanja prostorskih struktur, ter preiti $k$ oblikovanju take metodologije geografskega prouとevanja, ki na osnovi vzroxnosti in posledixnosti ter procesa oblikovanja diferenciranih socialnih skupin prebivalstva omogoca s prostorskimi proucevanji tako opredelitev problemov, ki je lahko osnova ali izhodišcc za regionalno prostorsko planiranje. Specifičnost geografske preobrazbe slovenske pokrajine je prav gotovo tudi odsev politicno-geografske lege in odprtosti meje s svojimi uxinki na oblikovanje obmejnih obmoxij, ki se zaradi prekomejnega sodelovanja na svoj način zrašcajo z narodnostno mešanimi obmoxji sosednjih držav Italije, Avstrije in Madžarske. Prav gotovo lahko geografska prouðevanja tega fenomena pomagajo pri opredelitvi koncepta nadaljnje regionalne preobrazbe $\mathrm{z}$ oblikovanjem takih prostorskih struktur, ki omogocajo SR Sloveniji kot obmejni regiji Jugoslavije integracijo $\mathrm{v}$ evropski prostor. $\mathrm{V}$ okviru koncipiranja integracije SR Slovenije z evropskim prostorom pa se odpirajo zapleteni problemi nadaljnjega razvoja slovenskega podeželja, saj so dosedanje raziskave pokazale, da so sicer glede na ostalo Jugoslavijo le manjsi deli kraške, alpske, predalpske in gri¿cvnate terciarne pokrajine SR Slovenije postala obmocja praznjenja prebivalstva in razkroja kulturne pokrajine. Toda danes tudi ostale dele slovenskega podeželja ogrožajo posledice nenað̌rtnega prostorskega sprošanja neagrarnih dejavnosti, కe zlasti industrije, in nenacrtna poselitev neagrarnega prebivalstva dnevnih migrantov na podeželju. Ti so si na obmoxjih, ki jih pogosto ogrožajo zemeljski usadi ob vremenskih neurjih, gradili stanovanjske hiše in drugo infrastrukturo, ne da bi pri tem upostevali naravne znaxilnosti terena. To se je ob zadnjih neurjih lepo pokazalo predvsem v Halozah in na Kozjanskem. Posledice neracionalnega ravnanja z naravo, kot je npr. nastajanje odlagališc odpadkov na podeželju, so se pokazale tudi ob pojavu zastrupljenosti pitne vode na Dravskem polju. Pianiranje nadaljnjega prostorskega razvoja se tudi ne bo moglo izogniti vprašanju usode nadaljnje izrabe kmetijskih 
zemljiß̌; ta so zaradi hitre urbanizacije in fosilizacije drobne zemljiske posesti, ki je slabše od tiste $v$ XIX. stolet ju, ko je prevladovalo ße roxno poljedelstvo, zato $v$ veliki meri presla v roke nekmeckih lastnikov. Tem lastnikom kmetijska zemlja vecinoma ne pomeni vec dodatnega eksistenčnega vira, temvex sredstvo za rekreacijo, vir dopolnilnega dohodka, a vendarle pomembno osnovo, ki jim omogoča pridelavo biolosko čistejse hrane.

Ne vem, ali se zavedamo, da je od kmetijstva odvisnega le se nekaj odstotkov, po moji presoji le \e okrog $3 \%$ prebivalstva Slovenije, ki je v vecji meri koncentrirano le $v$ severovzhodnem delu Slovenije. V osrednji in jugovzhodni Sioveniji so po vaseh le కe posamezni cisti kmetje, medtem ko v zahodnem in jugozahodnem delu Slovenije o socialni skupini kmetov, cksistencno odvisnih od zemlje, ne moremo vec govoriti. $\mathrm{V}$ preteklem razdobju smo iz politicnih razlogov vpeljali zakon o desthcktarskem maksimumu. Posledice tega so se pokazale $v$ prostorskem razvoju, zlasti pa pri ravnanju s kmetijsko zemljo, ki ni poznala postopnega združevanja zasebne kmetijske zemlje v kmetije z ustrezno povrß̌no, kot to narekuje tržno in tehnizirano kmetijsko gospodarstvo, temvec je ta zakon pogojeval drobljenje zemlje in pretirani razpad agrarne strukture prebivalstva. Proucevanje zakona o zašcitenih kmetijah bi nam prav tako lahko odprlo vrsto prostorsko relevantnih problemov, ki pogojujejo neustrezen sistem dedovanja, staranja lastnikov zemlje, ki nimajo ustrezne pobude za racionalno izrabo kmetijske zemlje in ustrezen razvoj in obnovo vasi ter s tem $v$ zvezi tudi celotnega podeželja.

Pri nasem usmerjanju geografije v bodoxnosti se bomo morali vprasati, kaj je v razmerah moderne industrijske družbe cilj geografije na znanstveno - raziskovalnem, izobraževalnem in vzgojnem podroxju. Na znanstveno - raziskovalnem podroxju je geografija prav gotovo lahko ucinkovita s svojimsocialno-geografskim, vzročno-posledixnim in problemskim znanstvenim konceptom, saj jo le-to lahko vodi v interdisciplinarnost in ponovno pridobitev vodilnega mesta med prostorskimi vedami, kot so ekologija, urbanizem in regionalno planiranje, pa tudi med drugimi vedami, ki svoje koncepte raziskav vse bolj snujejo $\mathrm{v}$ povezanosti s prostorom. $\mathrm{V}$ nekaterih državah Zahodne Evrope, zlasti v Avstriji, je geografija po Stevilu ur v osnovnih in srednjih Šolah obdržala položaj, kakrక̌nega smo imeli tako pri nas kot tudi pri njih pred štiridesetimi !eti. Vprałati se moramo po vzrokih, zakaj na nasih solah zmanjక̌jejo stevilo ur geografije $v$ ucnem procesu? Ne moremo trditi, da geografija v SRS v zadnjih dveh desetletjih ni imela možnosti za uveljavijanja $\mathrm{v}$ praksi. Vendar bo potrebno preveriti, v kakšni meri so dane možnosti geografom, ki delajo v planiranju, ekologiji in številnih drugih dejvnostih pri razvijanju in uveljavljanju medernega koncepta geografije kot analitske in prostorske znanosti. Če želimo uveljavljati tiste prvine geografske znanosti, ki jih družba eksistenæno potrebuje, se bomo morali temeljito zemisliti, kako $v$ bodoce organizirati delo na podroxju geografije, da bo ta lahko 
opravljala svoje naloge, ce se bo seveda sama razvijala v skladu z razmerami urbane in informacijske družbe. Tudi koncept socialne geografije, ki ga danes razvijamo in ki se je ponekod bolj, drugod pa manj ucinkovito uveljavil $v$ novi družbi, je potrebno dopolnjevati tako s teoretixnega kot tudi $\mathrm{z}$ metodološkega vidika spreminjanja prostorske strukture. 


\section{DER WEG VON ANTHROPO - ZUR SOZIALGEOGRAPHIE AN DER UNIVERSITÄT VON LJUBLJANA}

Die Geographie an der Universităt von Ljubljana entwickelte sich in den letzten siebzig Jahren im allgemeinen ăhnlich wie die Europas, wobei sie, in Anbetracht der neuen raumrelevanten Probleme besonders die raschen Wandlungen der răumlich-statischen und klassischen Agrargesellschaft in eine neue, modernere und flexieblere Industriegesellschaft verfolgte und studierte. Dic Professoren Melik und Ilesic, in den Zwischenkriegsjahren führende Geographen Sloweniens, haben im Rahmen ihrer regional- und physischgeographischen Studien schon damals den Auswirkungen der menschlichen Tătigkeiten und Aktivităten, besonders den sozialgeographischen Gruppen der nichtagraren Bevolkerung, ihr Interesse gewidmet. Diese Themen wurden erneut in Meliks Monographien, die Slowenien und ihre cinzelne Landesteile beschrieben, aufgegriffen und als sogenannte "anthropo - soziale Faktoren" in die Geographie Sloweniens eingeführt. Der Autor der Monographien hat die Möglichkeit die Auswirkungen der Almwirtschaft genauestens zu studieren genutzt und in diesem Zusammenhang den Einfluss der an diesem Wirtschaftszweig gebundenen Bevölkerung auf die Wandlung der Alpenlandschaft aufmerksam gemacht.

Bis in die fünfziger Jahre haben beide Professoren ihre Untersuchungen auch den Problemen der städtischen und agraren Siedlungen und der darin wohnenden Bevölkerung ihr Interesse gewidmet. Ein bedeutender Beitrag wurde auch im Rahmen spezyphischer Forschungen der landwirtschaftlichen Ueberbevơikerung und der Ineffizienz băuerlicher Arbeit geleistet.

In den letzten zwanzig Jahren hatte die slowenische Geographie ihr Interesse den neuen Raumstrukturen, verschiedenen und differenzierten Funktionen und den Wandlungsprozessen besonders in periphären Gebieten, geschenkt. Die Auswirkungen der Industrialisierung und Urbanisierung und die damit verbundenen Probleme, besonders der Ballungs- und Abwanderungsräume wurden genauestens untersucht. Die slowenische Anthropo-Sozialgeographie bemüht sich neuerdings die Frage der national gemischten und weniger entwickelten Grenzlandschaften zu erlăutern und Lơsungen vorzuschlagen. Diese sind nur im Sinne der grenzüberschreitenden Zusammenarbeit zwischen den benachbarten und auch mit Slowenen besiedelten Gebieten in Italien, Oesterreich und Ungarn zu sehen. 